\title{
Awareness of manufacturing defect of the chest drain bottle
}

Cagatay Tezel, Mustafa Vayvada, Talha Dogruyol

Chest tubes and bottles are some of the simplest devices used in medical practice. A chest drain system involves four components: drain tubing, a valve (underwater seal or flutter valve), a collection chamber, and an optional suction control device [1].

The classic underwater seal drainage system requires a bottle connected by tubing. The bottle provides the collection chamber. Fluid and air can egress from the tube. The vacuum produced by inhalation draws fluid into the tubing, but does not allow air to be re-introduced into the pleural cavity. The intrapleural vacuum can be countered by the application of suction to the third bottle, the suction control. In addition to the afferent and efferent tubes, the suction control bottle has a third tube open to air. The depth the tube penetrates below the fluid level determines the degree of suction. The "water seal" chamber acts as a one-way valve.

We wish to share an undesirable situation that we faced concerning a manufacturing defect of a chest tube bottle. The chest drainage system comprised a $2000 \mathrm{ml}$ bottle and tube which formed part of a one-piece system. In this particular instance, the chest tube bottle of a patient who had undergone decortication had been planned to be changed in the usual way. We changed the filled bottle but, unfortunately, we failed to notice the defect in its replacement. Soon after, continuous bubbling was seen in the bottle. Until now, we had never come across such a manufacturing defect (Figure 1). None of the other chest drains have had any problem. The defect has since been reported.

We therefore conclude that everyone involved in chest tube management should pay attention to checking the tubes and the bottles each time before their use.

\section{Key words}

Patient safety, postoperative care
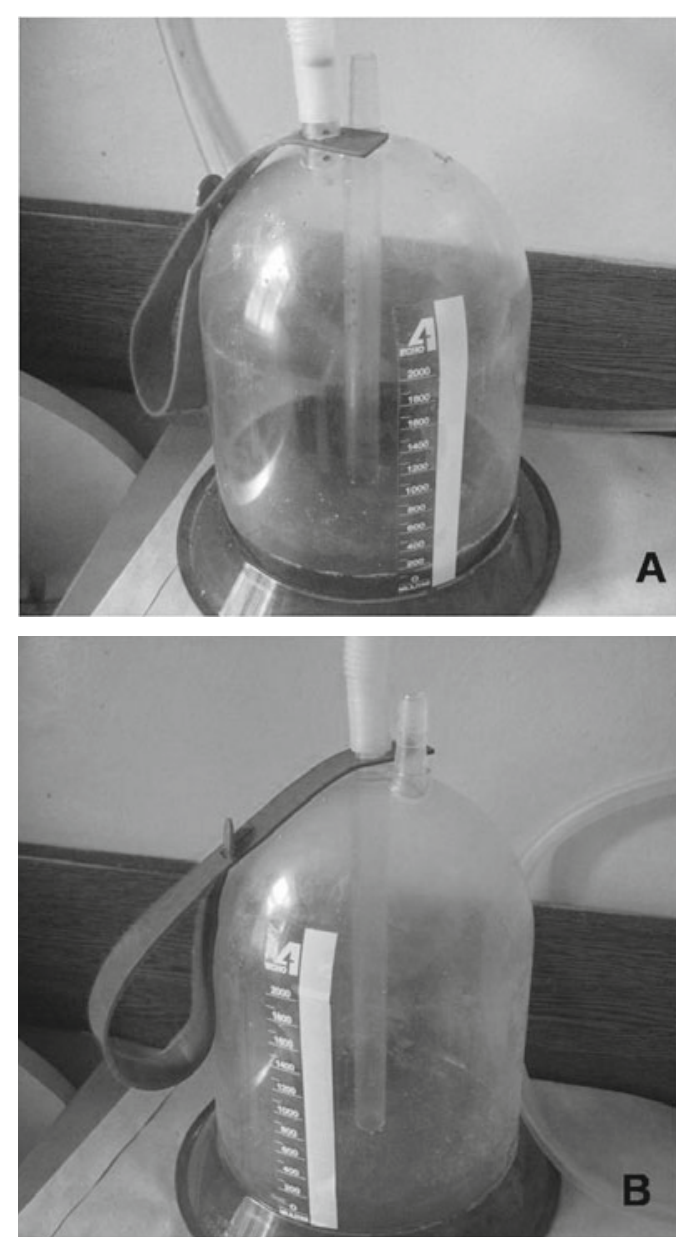

Figure 1. Find the differences between the pictures $\mathrm{A}$ (false) and B (true)

\section{References}

1. Nandi P. Chest tubes and water seal drainage. The Bulletin of Hong Kong Medical Association; 1977; 20:41-8

\footnotetext{
Cagatay Tezel, Mustafa Vayvada, Talha Dogruyol Department of Thoracic Surgery, Sureyyapasa Chest Diseases and Thoracic Surgery Teaching Hospital, Istanbul, Turkey

Corresponding author: Cagatay Tezel, Assoc Prof Caferaga mah. Gül sok Budak apt. 1/6, Moda Kadiköy Istanbul, Turkey GSM: 0090505 2600050, Fax: 00902163486491

E-mail: cagataytezel@hotmail.com
} 